\title{
Morphological and Physiological Responses of Maize (Zea mays L.) Seeds Grown under Increasing Concentrations of Chlorantraniliprole Insecticide
}

\author{
Semra Kilic*, Ragbet Ezgi Duran, Yasemin Coskun \\ Department of Biology, Faculty of Arts and Sciences, Suleyman Demirel University, 32260, Isparta, Turkey
}

Received: 12 August 2014

Accepted: 23 September 2014

\begin{abstract}
The inhibitory effects on biological properties of maize (Zea mays L. saccharata Sturt) seeds treated with chlorantraniliprole (CAP) were examined under greenhouse conditions. Maize seeds were exposed to environmentally relevant doses $(0.08,0.1,0.2,0.3,0.4$, and $0.5 \mathrm{ppm})$ of CAP. On day 7 of germination, morphological, anatomical, and physiological responses were determined. The most devastating inhibitory effect on germination parameters of maize seeds was on coleoptile length (90\%) in $0.5 \mathrm{ppm}$ insecticide concentration. Increasing concentrations of CAP resulted in decreased stomata density, compared with control. Similar results were also observed in stomata dimensions. On the other hand, high concentrations of CAP led to phytotoxic effects on photosynthetic pigments such as chlorophyll $a$, chlorophyll $b$, and carotenoid. On the contrary, the amount of anthocyanin and proline increased in proportion to increasing dosages, despite a reduction in growth. The results showed that all investigated parameters (except for proline and anthocyanin) significantly decreased with increasing insecticide dosages, compared to control $(p<0.05)$. The changes, particularly stomatal responses, and the amount of proline and anthocyanin on the leaves of the plants exposed to CAP stress, were determined as more sensitive parameters to detect insecticidal damage.
\end{abstract}

Keywords: chlorantraniliprole, seed germination, photosynthetic pigment, maize, insecticide

\section{Introduction}

Insecticides are toxic chemicals that are spread into agricultural production to prevent or control pests in an effort to reduce or eliminate yield losses and maintain high product quality. Substantial usage of insecticides has led to their increasing accumulation in soil, air, and water [1]. The long-term persistence and bioaccumulation of these chemicals are known to influence organisms by breaking all metabolic processes that are common to both target and non-target populations [2]. Although pesticides are chemi-

*e-mail: semrakilic@sdu.edu.tr cals applied in order to remove various pests with the aim of protecting agricultural products, their use raises toxicological effects on morphological, physiological, and genetic factors [3] of nontarget organisms, and on the environment as well. Therefore, the widespread use of pesticides in recent years has raised concerns about their persistence in soil, air, and water due to their adverse effects on human health and environment. The responses of plants to various chemical stress may be used as biomarkers of environmental pollution caused by pesticides [4].

Chlorantraniliprole (CAP) [3-bromo- $N$-[4-chloro-2methyl-6-(methylcarbamoyl)phenyl]-1-(3-chloropyridin-2yl)-1 $H$-pyrazole-5-carboxamide)] is a new class of insecti- 
cide and ryanodine receptor modulators [5]. Previous studies dealing with the impact of CAP in agriculture focused on their efficiency against insect pathogens [6], their accumulation in vegetables and fruits [7], crops [8], or their dissipation in several plants such as tomato [9] and cauliflower [10]. There has not been a certain amount of treatment concentration of CAP on plants, and therefore it is applied in very different concentrations [11]. For this reason, CAP used in excessive amounts leads to over-accumulation in the environment.

To date, no information has been available on the phytotoxicity of CAP, especially physiological and morphoanatomical responses in plants. On the other hand, pesticide residues cause persistent effects on plants [12], suppressing the biochemical and physiological responses in germination and seedling processes by inhibiting photosynthesis [13] and cell division [14]. However, with the investigation of modifications in germination and growth parameters of plants under various stresses that lead to changes on biochemical and physiological processes, anatomical and morphological anomalies that may be the visible signs of these changes can be determined [15]. Therefore, in this study, direct and indirect effects of CAP on the growth and development of the maize plants were evaluated via some growth parameters, such as seed germination, pigment content, and stomatal responses. We also investigated proline (non enzymatic antioxidant) accumulation, which is an important index for stress tolerance capacity in maize seedlings exposed to various levels of CAP in the present study.

\section{Materials and Methods}

Uniform-sized seeds $(n=25)$ of a commercial variety of maize (Zea mays L. saccharata Sturt.) were used as the test plant. The CAP was obtained from Altacor $35 \mathrm{WG}$.

The seeds of maize were surface sterilized with $0.5 \%$ sodium hypochlorite for $15 \mathrm{~min}$, followed by extensive washing in sterile distilled water. Seeds were exposed to CAP at various concentrations $(0.0,0.08,0.1,0.2,0.3,0.4$, and $0.5 \mathrm{ppm}$ ) for $72 \mathrm{~h}$. After pre-treatment, seeds were placed in $12 \mathrm{~cm}$ petri dishes lined with two layers of filter paper (Whatman 1) moistened with $10 \mathrm{ml}$ of the distilled water. They were placed at $25 \pm 1^{\circ} \mathrm{C}$ and light/dark $16 / 8 \mathrm{~h}$ for 7 days for germination. Each experiment was replicated three times. Seeds were considered to be germinated with emergence of the radicle.

Seeds germinated in each treatment were counted at the end of day $7^{\text {th }}$ and germination percentages were calculated according to Khan and Ungar [16]. The radicle and coleoptile lengths of the seedlings were measured with the help of a millimetric ruler.

Equal sized germinated seeds were transferred to a $1 \mathrm{~L}$ plastic pot filled with perlite for anatomical and physiological observations. Following transfer, seedlings were grown hydroponically in a growth chamber at $24 \pm 1^{\circ} \mathrm{C}$, under $16 / 8$ $\mathrm{h}$ light/dark regime, light intensity $160 \mu \mathrm{mol} / \mathrm{m}^{-2} / \mathrm{s}^{-1}$ with relative humudity of $60 \pm 5 \%$, and each pot was carefully watered with nutrient solution (Hoagland) added regularly every other day for 45 days. Epidermal tissue stripped from superficial sections of leaves was used to investigate the stomata and epidermis cells of upper (adaxial) and lower (abaxial) surfaces. The number of stomata $(s)$ and epidermal cells $(e)$ were counted in each field at independent measurements $\left(0.016 \mathrm{~mm}^{2}\right)$. Stomata density was based on an average of 50 microscopic field. Stomatal index (SI) was calculated using the formula $[s /(e+s)] \times 100$ described by Meidner and Mansfield [17]. Stomata magnitudes (length and width) were defined using an ocular micrometer under light microscope (40 X object and $10 \mathrm{X}$ ocular).

Pigments, including chlorophyll $a(\mathrm{Chl} a)$ and $b(\mathrm{Chl} b)$ and carotenoids, as well as anthocyanins were analyzed spectrophotometrically according to Sims and Gamon [18].

The proline content was extracted from leaf samples of $100 \mathrm{mg}$ FW with $2 \mathrm{ml}$ of $40 \%$ methanol according to Bates et al. [19].

\section{Statistical Analysis}

One-way ANOVA analysis was used to describe growth parameters and determine statistical significance. Duncan's Multiple Range Test was applied to compare means ( \pm SD) for at least two independent assays with three replicates using SPSS software 13.0. Graph images for all experimental data were generated to determine whether the mean values between the control group and insecticide treatments and also between each treatment was significantly different. The statistical significance level was taken as $\mathrm{p}<0.05$.

\section{Results and Discussion}

Insecticide treatment led to different morphological and physiological responses as parallel with increasing CAP concentrations in maize seeds and seedlings. Our results indicated strong negative effects of CAP on seed germination $(p<0.05)$, and the adverse effects enhanced with dosage elevation (Fig. 1). Germination percentage, coleoptile and radicula length, and radicula number of the maize exposed to all concentrations of CAP were lower than those in the control. At the highest concentration of CAP $(0.5 \mathrm{ppm})$, germination percentage was reduced to $72 \%$ of the control (Fig. 1a). However, germination percentage was very sensitive to CAP stress, and even increasing the concentration of CAP from $0.4 \mathrm{ppm}$ to $0.5 \mathrm{ppm}$ resulted in a $50 \%$ reduction $(\mathrm{p}<0.05)$. A similar result was observed for radicula length $(74 \%)$ and radicula number $(72 \%)$ of maize exposed to CAP at $0.5 \mathrm{ppm}$ compared with the control (Fig. 1b, d). They decreased with increasing concentration level of CAP, and the most devastating impact was the reduction in coleoptile length (90\%) at $0.5 \mathrm{ppm}$ (Fig. 1c). The results indicated that the significant reduction in the germination rate corresponded with the reduction in radicula and coleoptile lengths and radicula count. Therefore, the delay in growth of maize can be explained by suppression of germination under CAP stress.

Seed germination is a complex adaptive trait of plants that is influenced by environmental factors [20], and is a stage of plant growth where there is a particular sensitivity 
to contaminants like pesticides [21]. Pesticides have shown inhibitory effects on germination. Calvelo Pereira et al. [22] investigated the phytotoxicity effect of hexachlorocyclohexane on germination and early growth of different plant species (Hordeum vulgare L., Brassica sp., Phaseoulus vulgaris L.) and determined that the rate of germination and seedling vigour was strongly affected in plants exposed to it. The present study determined that increasing concentrations of CAP reduced germination parameters of maize. These adverse effects on maize seeds may be caused by the toxic effect of CAP accumulation.

The stomata count varied in adaxial and abaxial surfaces of leaves under CAP-induced stress (Fig. 2). In general, the stomata count of adaxial surfaces was lower than abaxial surfaces in untreatment. Increasing CAP concentration caused different responses in stomata and epidermis cell counts on the abaxial and adaxial surfaces of maize leaves. In seedlings exposed to CAP at 0.08-0.5 ppm, stomata count in leaves decreased 8-60 percent in adaxial surfaces, and 2-53 percent in abaxial surfaces compared with control. Similar results were observed in epidermis cell counts of both adaxial and abaxial surfaces of leaves. Stomatal index for adaxial and abaxial surfaces of leaves were determined to be lower than those of control plants. CAP treatment caused a statistically significant decrease in stomatal index of both surfaces in leaves $(p<0.05)$, especially the highest concentration $(0.5 \mathrm{ppm})$ of insecticide treatment, causing a further decrease of 46 percent in the control group's stomatal index of upper leaf surfaces. The fact that this decrease was higher on adaxial surfaces than on abaxial surfaces is in parallel with a higher reduction of stomata and epidermis cell counts on upper surfaces

a)

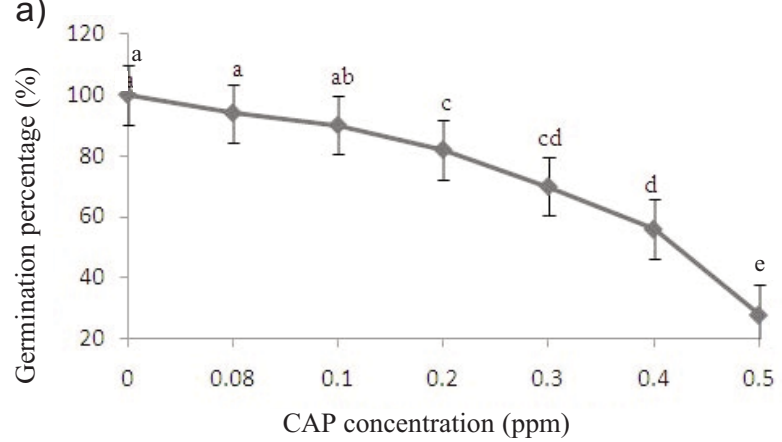

b)

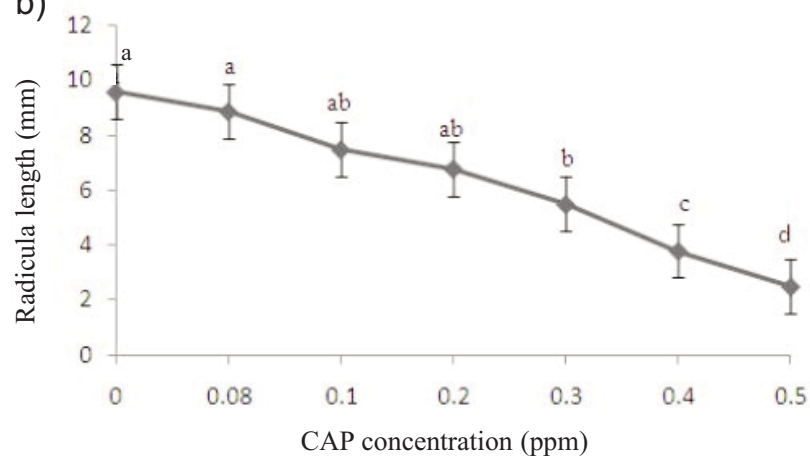

than on lower surfaces as insecticide concentration increases (Fig. 2a). However, the stomata concentration on both surfaces of maize leaves exposed to CAP treatment showed the most devastating effect at the concentration of $0.4 \mathrm{ppm}$ with $29 \%$ reduction in adaxial surface and $28 \%$ reduction in abaxial surface, compared with $0.5 \mathrm{ppm}$ of CAP treatment. This adverse effect increased at 0.5 ppm (Fig. 2a, b). Photosynthesis is directly proportional to stomata concentration [23]. In our study, the fact that stoma concentration reduces in parallel with the pesticide concentration involved is an indication that the rate of photosynthesis will reduce at the same level.

On the other hand, this study also examined stomata sizes (length and width) on both surfaces of leaves. The stomata size on the adaxial surface were larger than those on the abaxial surface, it was seen that stomata length and width decreased with increasing concentrations of CAP, compared with control (Fig. 2 c, d). These results were found to be statistically significant in all treatments groups $(\mathrm{p}<0.05)$. The smallest stomata cell was observed on the adaxial surfaces of leaves grown at $0.5 \mathrm{ppm}$ concentration of CAP, while the largest were on the abaxial surface of leaves grown at $0.0 \mathrm{ppm}$ (untreatment) of control group. However, while CAP application decreased these parameters by $80 \%$ on the adaxial surface in $0.5 \mathrm{ppm}$ concentration of CAP, stomata size on the abaxial surface of the leaf decreased by $66 \%$ at the same concentration. These results indicate that CAP exposure can show a significant negative impact on maize plants. The phytotoxic effects of this chemical also affected stoma sizes negatively. Stoma size reduced more on upper surfaces of maize leaves exposed to CAP than on lower surfaces.

C)

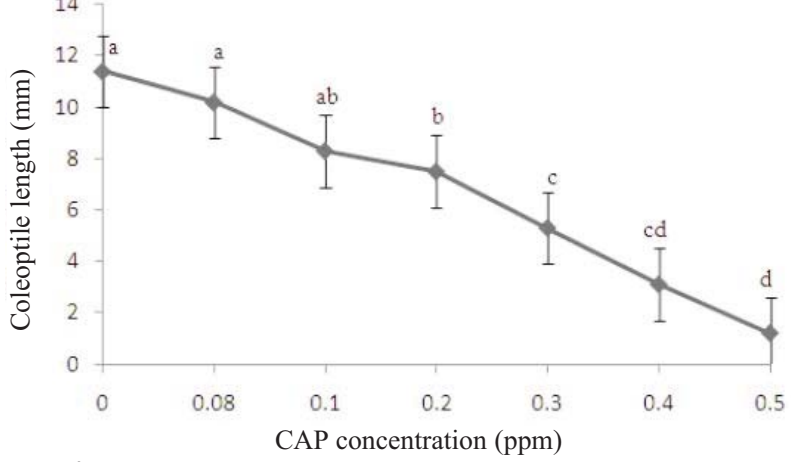

d)

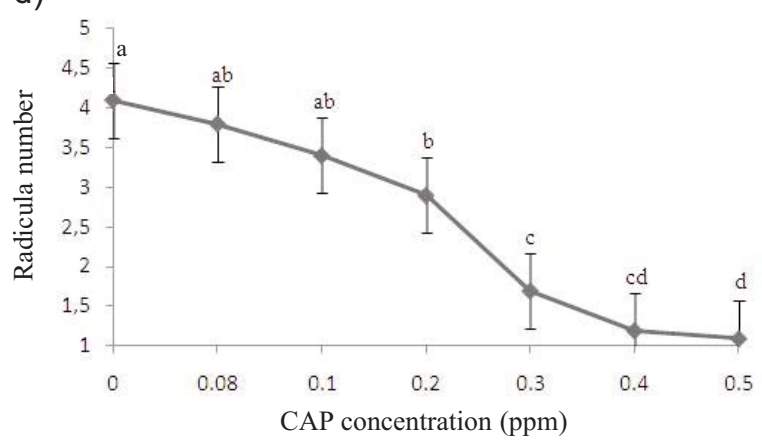

Fig. 1. Effects of different concentrations of CAP on germination (a), radicula length (b), coleoptile length (c), and radicula number (d) of maize seeds. Data represent the mean values $( \pm \mathrm{SD})$. Different letters indicate a statistically significant difference at $\mathrm{p}<0.05$. 
This destructive effect of pesticide on stomata density and size is similar to the equation pro application on tomato plants [24]. On the other hand, stomatal density was significantly reduced in tomato plants exposed to fosetyl-Al stress [25]. Moreover, Toscano et al. [26] found that various insecticides like parathion and permethrin had significant effects on stomatal conductance rates of lettuce physiology. But no information was available on stomatal responses of maize to CAP exposure. The fact that stomata count decreases as concentration of CAP increases in maize seeds grown under CAP stress shows that the photosynthesis rate of these plants can also be affected negatively.

Stomata are pores on leaf surfaces that function in exchange for $\mathrm{CO}_{2}$ and $\mathrm{O}_{2}$, which are necessary for photosynthesis, and many environmental factors such as biotic and abiotic stress can cause significant changes in stomatal responses [27]. Morever, stomatal responses may limit the photosynthesis when plants are exposed to sigma broad stress conditions [28]. In particular, chemicals used for eliminating various harmful organisms cause destructive effects on plants in agricultural environments, leading to toxic effects on stomatal responses.

The pigment content was significantly higher in the control than in each of the treatments, which showed significant difference among each other $(\mathrm{p}<0.05)$. The differences in pigment concentrations were negatively associated with the increase in insecticide concentration. Maize seeds exposed to CAP showed significant decreases in Chl $a$ (Fig. 3a), Chl $b$ (Fig. 3b), and carotenoid contents (Fig. 3c) by
$70 \%, 63 \%$, and $65 \%$, respectively, at the highest concentration of CAP in comparison with the control plants. Under CAP stress, the amount of chlorophyll $a$ content of maize leaves was more affected than the amount of chlorophyll $b$ and carotenoid contents. The most damaging effect appeared with a reduction by $70 \%$ of $\mathrm{Chl} a$ content at the highest concentration of CAP compared to control. Moreover, compared with other treatments, the adverse effect of CAP treatment on photosynthetic pigment content was observed more, particularly at 0.3-0.4 ppm CAP concentrations. For example, the $\mathrm{Chl} a$ content of maize seeds treated by $0.08,0.1,0.2,0.3,0.4$, and $0.5 \mathrm{ppm}$ of CAP were decreased by $13 \%, 20 \%, 24 \%, 31 \%, 53 \%$, and $70 \%$, respectively, compared to the control $(\mathrm{p}<0.05)$. The relative decrease in the Chl $a$ content is significantly more than that of $\mathrm{Chl} b$ and carotenoid contents, especially maize plants treated with 0.3-0.4 ppm of CAP, showing a more significant decrease in Chl $a$ contents by $42 \%$ compared with the other treatments. Chl $b$ decreased $23 \%$ in CAP's 0.4-0.5 ppm concentration compared to $0.5 \mathrm{ppm}$. On the other hand, the concentration interval having the most damaging effect on carotenoid content was found to be $0.4-0.5 \mathrm{ppm}$ $(p<0.05)$ with a $66 \%$ decrease. But the rate of reduction of carotenoid content was more than $\mathrm{Chl} b$ content. Photosynthetic pigment content is an important indicator for determining plant photosynthesis ratio [28]. These pigments are inhibited in the presence of stress, thus altering the photosynthesis of plants [29]. However, when exposed to mancozeb, $\mathrm{Chl}$ and carotenoid contents decreased in let-
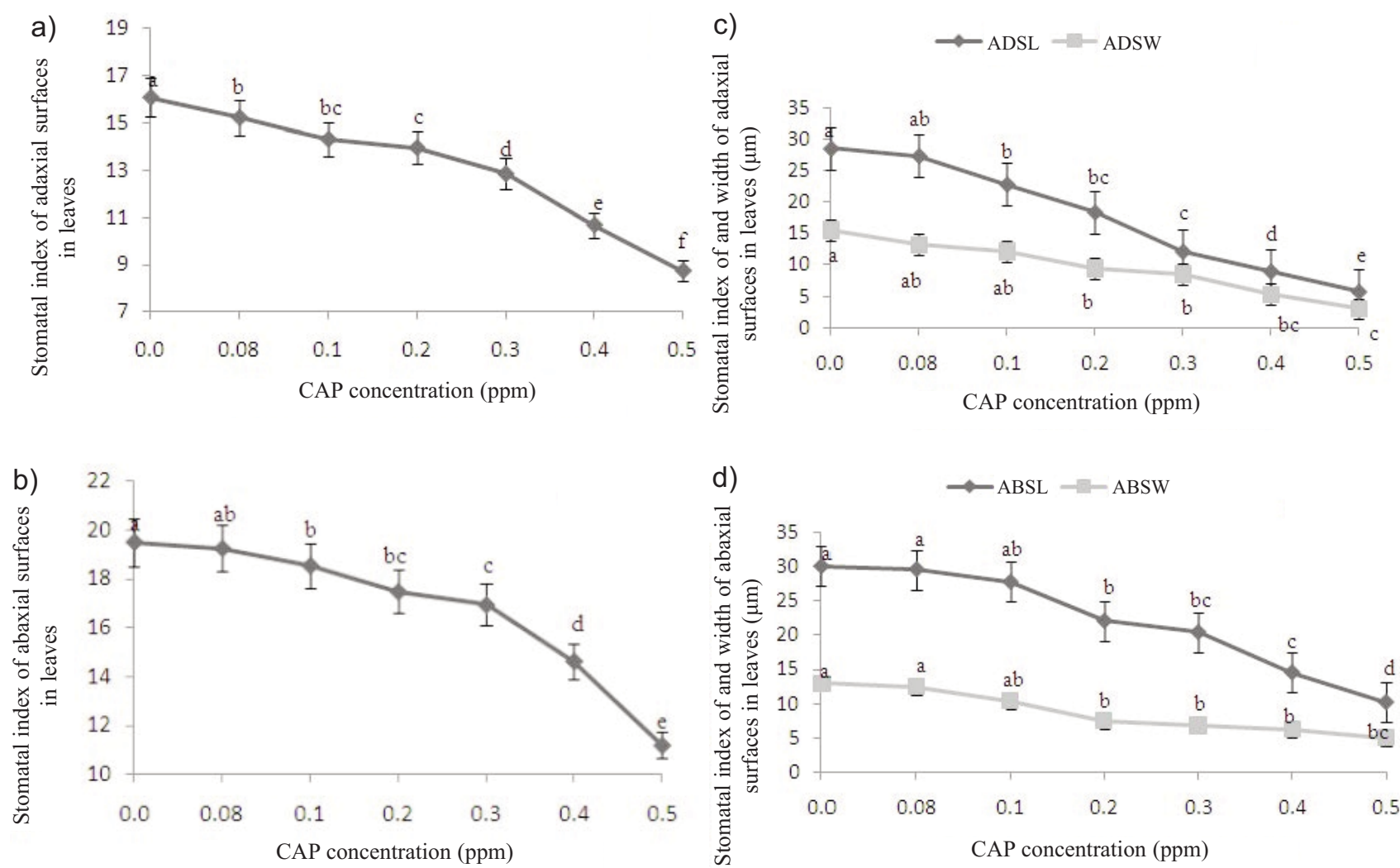

Fig. 2. Stomatal variation in adaxial and abaxial epidermis of leaves of maize plants treated with different concentrations of CAP: adaxial surface stomatal index (a), abaxial surface stomatal index (b), adaxial surface stomata length (ADSL) and width (ADSW) (c), and abaxial surface stomata length (ABSL) and width (ABSW) (d). Data represent the mean values $( \pm \mathrm{SD})$. Different letters indicate statistically significant difference at $\mathrm{p}<0.05$. 

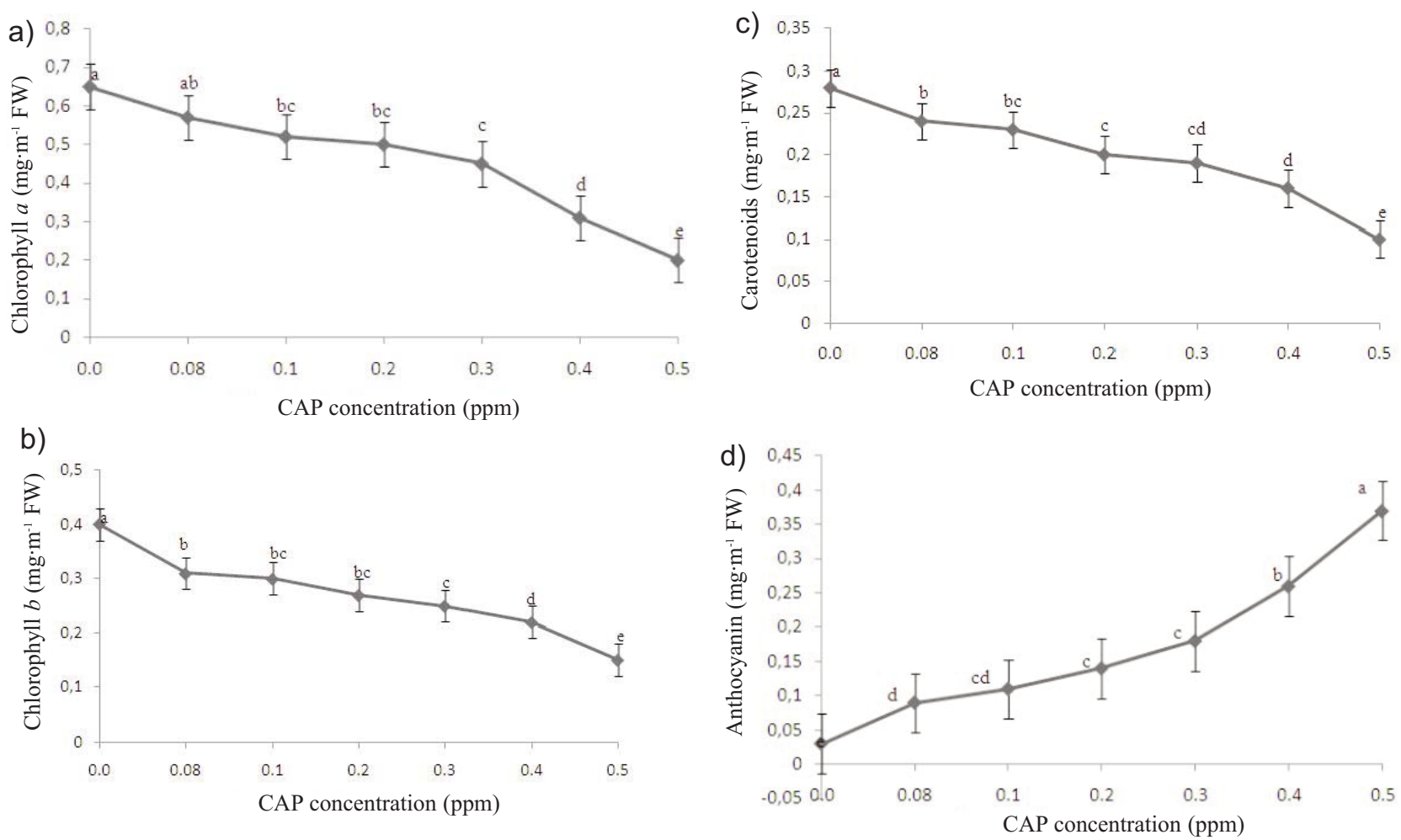

Fig. 3. Variations in Chlorophyll $a$ (a), Chlorophyll $b$ (b), carotenoid (c), and anthocyanin (d) contents of maize leaves treated with different concentrations of CAP. Values with different letters are significantly $(\mathrm{p}<0.05)$ different from each other.

tuce leaves, which in turn caused the pigment-protein complexes of the photosynthetic apparatus to be less stable, and photosynthetic pigments degraded more easily upon pesticide exposure [30]. Moreover, insecticides might inhibit the biosynthesis of chlorophyll by slowing down or stopping synthesis of enzymes responsible for the synthesis of photosynthetic pigments [31].

Pigment contents are well known to decrease with treatment of various pesticides, such as insecticides [32], herbicides [33], and fungicides [34]. Anthocyanins are an important and widespread group of pigments that are found in flowers, fruits and, rarely, epidermis of leaves. However, anthocyanins that cannot play a direct role in photosynthesis are widely distributed in photosynthetic tissues, such as leaves of plants that are exposed to stress. In this study, the anthocyanin content of maize leaves exposed to CAP showed significant parallelism with its increasing concentration, unlike other pigments (Fig. 3d). The increase in anthocyanin content was $67 \%, 73 \%, 79 \%, 84 \%, 89 \%$, and $92 \%$ exposed to $0.08,0.1,0.2,0.3,0.4$, and $0.5 \mathrm{ppm}$ of CAP, respectively, compared with control $(p<0.05)$. Different concentrations of CAP stimulated the anthocyanin content. Similar accumulation of anthocyanin was observed by Alla and Younis [35] in maize and soybean exposed to pesticide stress. Anthocyanins are responsible for tolerance to various stress factors such as drought or resistance to pathogens [36]. Furthermore, anthocyanins known as being powerful antioxidants increased its accumulation when the plant was exposed to various stresses [37]. Therefore, increase in the anthocyanin content in the leaves of maize exposed to increasing concentrations of CAP might have resulted due to inducing the expression of

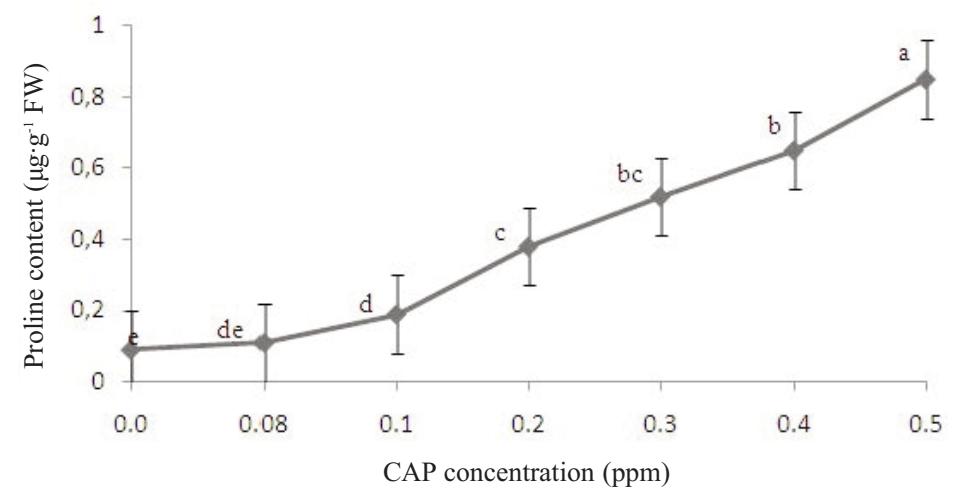

Fig. 4. Variation in proline content of maize leaves treated with different concentrations of CAP. Data represent the mean values $( \pm \mathrm{SD})$. Different letters indicate statistically significant differences at $\mathrm{p}<0.05$. 
genes involved with protection against many environmental stresses [38].

CAP exposure induced a significant increase in proline content (Fig. 4). Its content was enhanced compared with control group by $19 \%, 53 \%, 77 \%, 83 \%, 87 \%$, and $90 \%$ at $0.08,0.1,0.2,0.3,0.4$, and 0.5 ppm of CAP concentrations, respectively, showing a significant positive correlation with increasing concentrations of CAP. Morever, $0.1 \mathrm{ppm}$ concentration of CAP showed the highest trigger effect (increase ratio 120\%). The increases of proline content were observed after CAP exposure, and this might be an exhaustive effect in plants exposed to insecticides. The increase in proline content of insecticide treated plants was associated with high accumulation of proline due to increasing concentration of CAP. Proline content is an essential indicator in that it follows an increasing path in plants exposed to various stress factors [39]. Increases of proline content were also observed after being exposed to various pesticide stresses [30]. Proline is a non-enzymatic antioxidant that plays a protective role in membrane structure of living cells of plants exposed to various stress [40]. The results on the changes in the content of non-enzymatic antioxidants under the effects of pesticide treatments very clearly indicated the significant stimulation of proline accumulation. The stimulation was stronger with increasing concentrations of pesticide treatments. This may suggest that proline could play a crucial role in the resistance of maize to alleviate negative effects of insecticide stress.

\section{Conclusion}

CAP stress altered seed germination, stomatal responses in leaves, photosynhetic pigments, and proline content of maize plants. Although the phytotoxic effect of various chemicals can be tolerated to a certain amount, most of the plants showed growth and development disorders, particularly in higher concentrations. This effect showed that seed germination was negatively associated with CAP concentration. A similar effect was observed in stomatal responses in leaves of maize. In general, stomata density and stomata dimensions declined in both its adaxial and abaxial surfaces. On the other hand, photosynthetic pigment contents also reduced due to slowing down of their biosynthesis with increasing CAP stress, except for anthocyanin. Increasing CAP exposure triggered a significant increase in proline and anthocyanin content. CAP treatment caused photosynthetic pigments to be inhibited and photosynthesis was affected adversely in the end. This situation led to a decline in the growth and development of plants. This adverse effect continued with respect to CAP concentration. On the other hand, although a significant decline was observed in the germination environment and growth parameters, contents of anthocyanin, which has a protective role, and proline increased. However, the increase in protective antioxidative substances couldn't prevent the adverse effects of the chemical on germination and growth parameters and thus growth rate declined. Therefore, with their increasing residues both in the stage of employment and in the envi- ronment, the adverse effect of these chemicals on all organisms is inevitable even if the recommended amount is employed.

\section{References}

1. HARNPICHARNCHAI K., CHAIEAR N., CHARERNTANYARAK L. Residues of organophosphate pesticides used in vegetable cultivation in ambient air, surface water and soil in Bueng Niam Subdistrict, Khon Kaen, Thailand. Southeast. Asian. J. Trop. Med. Public. Health. 44, (6), 1088, 2013.

2. JAFARI M., SALEHI M., AHMADI S., ASGARI A., ABASNEZHAD M., HAJIGHOLAMALI M. The role of oxidative stress in diazinon-induced tissues toxicity in Wistar and Norway rats. Toxicol. Mech. Methods. 22, (8), 638, 2012.

3. KUMAR G., CHAUDHARY N. Mitotoxic effect of 2, 4-D and endosulfan in root meristems of Hordeum vulgare. Chromos. Bot. 7, (2), 73, 2012.

4. SOARE L.C., DOBRESCU C.M., POPESCU M., BOERU A.G. The Effects of Some Pesticides on Spore Germination and Gametophyte Differentiation in Athyrium filix-femina (L.) Roth. and Polypodium vulgare L. Not. Bot. Horti. Agrobo. 41, (2), 458, 2013.

5. CORDOVA D., BENNER E.A., SACHER M.D., RAUH J.J., SOPA J.S., LAHM G.P., SELBY T.P., STEVENSON T.M., FLEXNER L., GUTTERIGE S., RHOADES D.F., WU L., SMITH R.M., TAO Y. Anthranilic diamides: a new class of insecticides with a novel mode of action, ryanodine receptor activation. Pestic. Biochem. Phys. 84, 196, 2006.

6. GONG W., YAN H-H., GAO L., GUO Y-Y., XUE C-B. Chlorantraniliprole resistance in the diamondback moth (Lepidoptera: Plutellidae). J. Econ. Entomol. 107, (2), 806, 2014.

7. XU P., REN Y., ZHPU Z., LIU A., ZHANG H. Determination of Chlorantraniliprole in Vegetables, Fruits and Grains by SPE Clean-Up and LC-UV. Chromatographia. 72, (7-8), 763, 2010.

8. ZHANG J.M., CHAI W.G., WU Y.L. Residues of chlorantraniliprole in rice field ecosystem. Chemosphere. 87, (2), 132, 2012.

9. MALHAT F., ABDALLAH H., HEGAZY I. Dissipation of chlorantraniliprole in tomato fruits and soil. Bull. Environ. Contam. Toxicol. 88, (3), 349, 2012.

10. KAR A., MANDAL K., SINGH B. Environmental fate of chlorantraniliprole residues on cauliflower using QuEChERS technique. Environ. Monit. Assess. 185, (2), 1255, 2013.

11. HAN W., ZHANG S., SHEN F., LIU M., REN C., GAO X. Residual toxicity and sublethal effects of chlorantraniliprole on Plutella xylostella (Lepidoptera: Plutellidae). Pest. Manag. Sci. 68, 969, 2012.

12. KHANNA N., SHARMA S. Allium Cepa Root Chromosomal Aberration Assay: A Review. Indian. J. Pharm. Biol. Res. 1, (3), 105, 2013.

13. MISHRA V., SRIVASTAVA G., PRASAD S.M., ABRAHAM G. Growth, photosynthetic pigments and photosynthetic activity during seedling stage of cowpea (Vigna unguiculata) in response to UV-B and dimethoate. Pestic. Biochem. Phys. 92, (1), 30, 2008.

14. SIDDIQUI S., MEGHVANSI M.K., KHAN S.S. Glyphosate, alachor and maleic hydrazide have genotoxic effect on Trigonella foenum-graecum L. Bull. Environ. Contam. Toxicol. 88, (5), 659, 2012. 
15. ANASTASOV H. Influence of oxyfluorfen on some anatomic indices in the leaves of Virginia tobacco plant (Nicotiana tabacum L.). Second Balkan Conference on Biology, 21-23 May, Plovdiv, 50 Years University of Plovdiv, 2010.

16. KHAN M.A., UNGAR I.A. The effect of salinity and temperature on the germination of polymorphic seeds and growth of atriplex triangularis willd. American Journal of Botany. 71, (4), 481, 1984.

17. MEIDNER H., MANSFIELD T.A. Physiology of stomata. New York: McGraw Hill, pp. 178, 1968.

18. SIMS D.A., GAMON J.A. Relationships between leaf pigment content and spectral reflectance across a wide range of species, leaf structures and developmental stages. Rem. Sens. Environ. 81, (2-3), 337, 2002.

19. BATES L., WALDREN R.P., TEARE I.D. Rapid determination of free proline for water-stress studies. Plant and Soil. 39, (1), 205, 1973.

20. KOORNNEEF M., BENTSINK L., HILHORST H. Seed dormancy and germination. Curr. Opin. Plant. Biol. 5, (1), 33, 2002.

21. GOSWAMI M.R., BANERJEE P., SWARNAKAR S., MUKHOPADHYAY A. Carbaryl mediated biochemical alterations in Eggplant (Solanum melongena L.). Int. J. Res. Envir. Sci. Tech. 3, (2), 51, 2013.

22. CALVELO PEREIRA R., MONTERROSO C., MACIAS F. Phytotoxicity of hexachlorocyclohexane: Effect on germination and early growth of different plant species. Chemosphere. 79, 326, 2010.

23. LAKE J.A., WOODWARD F.I., QUICK W.P. Long-distance $\mathrm{CO}_{2}$ signalling in plants. J. Exp. Bot. 53, 183, 2002.

24. OZTURK I. The effect of equation pro (Fungicide) application on stomata in tomato (Lycopersicon esculentum Mill.) plants. J. Agric. Sci. 12, (2), 195, 2006.

25. OZTURK CALI, I. The effect of fosetyl-Al application on stomata in tomato (Lycopersicon esculentum Mill.) plant. J. Plant. Breed. Crop. Sci. 1, (3), 045, 2009.

26. TOSCANO N.C., SANCES F.V., JOHNSON M.W., LAPRE L.F. Effect of various pesticides on lettuce physiology and yield. J. Econ. Entomol. 75, (4), 738, 1982.

27. HETHERINGTON A.M., WOODWARD F.I. The role of stomata in sensing and driving environmental change. Nature. 424, 901, 2003

28. YUAN X., GUO P., QI X., NING N., WANG H., WANG H., WANG X., YANG Y. Safety of herbicide Sigma Broad on Radix Isatidis (Isatis indigotica Fort.) seedlings and their photosynthetic physiological responses. Pestic. Biochem. Phys. 106, 45, 2013.
29. WIECZOREK J.K., WIECZOREK Z.J. Phytotoxicity and accumulation of anthracene applied to the foliage and sandy substrate in lettuce and radish plants. Ecotox. Environ. Safe. 66, 369, 2007.

30. DIAS M.C., FIGUEIREDO P., DUARTE I.F., GIL A.M., SANTOS C. Different responses of young and expanded lettuce leaves to fungicide Mancozeb: chlorophyll fluorescence, lipid peroxidation, pigments and proline content. Photosynthetica. 52, (1), 148, 2014.

31. BAOZHEN D., JIAYAO W., PIAO M., YUE Z., AIUJUM Q. The effects of imidacloprid on maize chlorophyll contents at different application times. Pestic. Sci. Adminis. 3, 57, 2013.

32. PANDEY J.K., GOPAL R. Laser-induced chlorophyll fluorescence: a technique for detection of dimethoate effect on chlorophyll content and photosynthetic activity of wheat plant. J. Fluoresc. 21, 785, 2011.

33. TAN W., LI Q., ZHAI H. Photosynthesis and growth responses of grapevine to acetochlor and fluoroglycofen. Pestic. Biochem. Phys. 103, 210, 2012.

34. RAJENDRAN U.M., KATHIRVEL E., NARAYANASWAMY A. Effects of a fungicide, an insecticide, and a biopesticide on Tolypothrix scytonemoides. Pestic. Biochem. Phys. 87, 164, 2007.

35. ALLA N.M.M., YOUNIS M.E. Herbicide effects on phenolic metabolism in maize (Zea mays L.) and soybean (Glycine $\max$ L.) seedlings. J. Exp. Bot. 46, 1731, 1995.

36. HIPSKIND J., WOOD K., NICHOLSON R.L. Localized stimulation of anthocyanin accumulation and delineation of pathogen ingress in maize genetically resistant to Bipolaris maydis race O. Physiol. Mol. Plant. P. 49, 247, 1996.

37. RIVERO R.M., RUIZ J.M., GARCIA P.C., LÓPEZLEFEBRE L.R., SÁNCHEZ E., ROMERO L. Resistance to cold and heat stress: accumulation of phenolic compounds in tomato and watermelon plants. Plant. Sci. 160, 315, 2001.

38. STEYN W.J., WAND S.J.E., HOLCROFT D.M., JACOPS G. Anthocyanins in vegetative tissues: a proposed unified function in photoprotection. New. Phytol. 155, 349, 2002.

39. KAVI KISHOR P.B., SANGAM S., AMRUTHA R.N., SRI LAXMI P., NAIDU K.R., RAO K.R.S.S., RAO S., REDDY K.J., THERIAPPAN P., SREENIVSULU N. Regulation of proline biosynthesis, degradation, uptake and transport in higher plants: Its implications in plant growth and abiotic stress tolerance. Curr. Sci. India. 88, 424, 2005.

40. ANJUM S.A., FAROOQ F., XIEA X., LIUA X., IJAZ M.F. Antioxidant defense system and proline accumulation enables hot pepper to perform better under drought. Sci. Hort. 140, 66, 2012. 
